\title{
AHP ve TOPSIS ile Farklı Kriter Ağırlıklandırma Yöntemlerinin Kullanılması ve Karar Verici Görüşleriyle Karşılaştırılması
}

\author{
Mert Durmuş ${ }^{1}$ \\ Nezih Tayyar ${ }^{2}$
}

AHP ve TOPSIS ile Farklı Kriter Ağırlıklandırma Yöntemlerinin Kullanılması ve Karar Verici Görüşleriyle Karşılaştırılması

\section{Öz}

Çok Kriterli Karar Verme (ÇKKV) problemlerinde kriter ağırıkları ve kullanılan yöntem problemin çözümüne doğrudan etki eder. Bu çalışmada AHP ve TOPSIS yöntemleri kullanılarak karar verici görüşlerine en yakın sonuçları veren yöntemlerin belirlenmesi amaçlanmıştır. Online alışveriş siteleri, internet kullanımının artmasıyla oldukça popüler bir hale gelmiştir. Buradan hareketle çalışmada kullanılmak üzere Türkiye'nin en bilinen online alışveriş sitelerinden üç tanesi alternatif olarak belirlenmiştir. Çalışmada güvenilirlik/gizlilik, ödeme kolaylığı, ürün bilgisi ve çeşitliliği ile web sitesi performansı olmak üzere dört kriter kullanılmıştır. AHP ve TOPSIS yöntemlerinin kriter ağırlıkları belirlenirken İkili Karşılaştırma yöntemi dışında Max100 ve SWARA yöntemlerinin de kullanılması çalışmayı daha önce yapılanlardan ayıran önemli bir özelliktir. Yapılan çalışma sonucunda en önemli kriterin Güvenilirlik/Gizlilik, en az önemli kriterin ise Web Sitesi Performansı olduğu görülmüştür. Aynı zamanda belirlenen kriterlere göre hepsiburada.com sitesinin katılımcıların gözünde en iyi online alışveriş sitesi olduğu sonucuna varılmıştır. Elde edilen bulgular ışığında kriter ağırlıklandırma yöntemlerinde Max100 ve SWARA yöntemlerinin İkili Karşılaştırma yöntemine göre, ÇKKV yöntemlerin de ise AHP'nin TOPSIS'e göre Karar Vericinin görüşlerine daha yakın sonuçlar verdiği görülmüştür.

Anahtar Kelimeler: Çok Kriterli Karar Verme (ÇKKV), AHP, TOPSIS, Max100, SWARA, İkili Karşılaştırma, Online Alışveriş, Kriter Ağırlıklandırma
Usage of Different Criterion Weighting Methods with AHP and TOPSIS and Comparison with Decision Makers' Opinions

\section{Abstract}

Criteria weights and the method used in the Multi Criteria Decision Making (MCDM) problems have a direct impact on the solution of the problem. In this study, it is aimed to determine the methods which give the closest results to the decision makers' opinions using AHP and TOPSIS methods. Online shopping sites have become very popular with the increase in internet usage. Three of Turkey's best-known online shopping sites have been identified as alternatives to be used in this study. Reliability / privacy, ease of payment, product information and variety, and website performance are the four criteria used in this study. The use of Max100 and SWARA methods apart from the Pairwise Comparison method is an important feature that separates the study from the previous studies while determining the criteria weights of the AHP and TOPSIS methods. The results indicate that the most important criterion in the study is reliability / privacy, and the least important criterion is Web Site Performance. At the same time, according to the criteria determined, hepsiburada.com site was the best online shopping site in the eyes of the participants. In the light of findings Max100 and SWARA methods provide closer results to decision makers' opinions than Pairwise Comparison in criteria weighting methods and AHP gives closer results to decision makers' opinions than TOPSIS in the methods of MCDM.

Keywords: Multiple Criteria Decision Making (MCDM), AHP, TOPSIS, Max100, SWARA, Pairwise Comparison, Online Shopping, Criteria Weightin

\section{Giriş}

Çok Kriterli Karar Verme (ÇKKV) problemleri; insanların hayatının her safhasında en çok karşılaştıkları problemlerin başında gelmektedir. Örneğin kişisel açıdan düşünüldüğünde dizüstü bilgisayarı, akıllı telefon, otomobil vb. ürünlerin satın alımında ve kurumsal bazda ise herhangi

\footnotetext{
${ }^{1}$ Arş. Gör., Uşak Üniversitesi iỉBF, İşletme Bölümü. mert.durmus@usak.edu.tr.

2 Doç. Dr., Uşak Üniversitesi IïBF, İşletme Bölümü. ntayyar@gmail.com.
} 
bir pozisyona eleman alımında ya da yeni açılacak bir fabrika, işletme vb. kurumlar için en uygun yerin bulunmasında belirlenen kriterlere göre seçim yapılması durumu ÇKKV problemlerinin insan hayatındaki yerini gösteren örneklerden bazılarıdır. Bu problemlerin çözümünde önemli bir yere sahip olan ÇKKV yöntemleri ve kriter ağırlıklandırma yöntemleri ile ilgili birçok çalışma yapılmıştır. Yapılan bu çalışmaların bazılarında ÇKKV yöntemleri, bazılarında ise kriter ağırlıklandırma yöntemleri etkinlik, tatmin düzeyi ve değişkenlik bakımından birbiriyle kıyaslanması amaçlanmıştır. Bu çalışmanın amacı ise; ÇKKV yöntemlerinde en sık kullanılan yöntemlerden ikisi olan AHP ve TOPSIS yöntemleri ile en iyi alışveriş sitesini seçmek, bu yöntemleri kullanırken kriter ağırlıklarını belirleme aşamasında Max100, SWARA ve İkili Karşılaştırma yöntemlerinden faydalanarak kriter ağırlıklarını elde etmek ve hepsinden önemlisi Max100, SWARA ve İkili Karşılaştırma yöntemlerine göre elde edilecek olan altı ayrı sonucu, değerlendirmeye katılan katıIımcıların anketin başında belirlemiş oldukları alternatif ve kriter sonuçlarıyla kıyaslayarak hangi kriter ağırlıklandırma yönteminin hangi ÇKKV yöntemiyle kullanıldığında daha tatmin edici bir sonuç verdiğine ulaşmaktır.

ÇKKV yöntemleriyle ilgili doğrudan ya da dolaylı olarak birçok çalışma yapılmıştır. ÇKKV yöntemlerinde çözümün en önemli adımlarından biri de kriter önemlerinin belirlenmesi sürecidir. Kriter önemlerinin belirlenmesi bazı ÇKKV yöntemlerinde doğrudan ilgili yöntem tarafından gerçekleştirilirken, bazılarında ise karar vericiler tarafından yapılmaktadır. Bu bağlamda kriter önemlerini belirlemek amacıyla geliştirilmiş birçok kriter ağırlıklandırma yöntemi bulunmaktadır (Zardari vd., 2014). Bu çalışmanın ÇKKV ve kriter ağırlıklandırma yöntemleriyle ilgili daha önce yapılan çalışmalardan farkı; AHP ve TOPSIS yöntemlerinde kriter ağırlıkları belirlenirken genellikle ikili Karşılaştırma yöntemi kullanıırken ilk kez bu çalışmayla kriter ağırlıklarının Max100 ve SWARA yöntemleriyle belirlenecek olmasıdır. Ayrıca elde edilecek sonuçların karar verici görüşleriyle karşılaştırılması kriter ağırlıklandırma yöntemlerinden hangisinin AHP veya TOPSIS' de kullanıldığında daha tatmin edici sonuca ulaşıldığını ortaya çıkarabilecek olması daha önce yapılan çalışmalardan ayıran başka bir önemli nokta olacaktır.

\section{Literatür}

Karar verme işlevi; insanların hayatın her anında karşılaştıkları bir durumdur. Karar verme; kişinin kendi hayatı, çevresi veya çalıştığı iş yeri için belirlemiş olduğu amaç ve hedefe ulaşmak adına ilgili alternatif durumlar arasından seçim yapma eylemi olarak tanımlanabilmektedir (Forman ve Selly, 2001). Karar verme işlevi gerçekleştirilirken belirtilen alternatiflerin yanında verilecek kararın sonuçlarına etkisi bulunan kriter sayısının da artması karar verme sürecini zorlaştırmaktadır. Bu tür birbiriyle çelişen birçok kriterin yer aldığı alternatifler arasından seçim yapma işlevi Çok Kriterli Karar Verme (ÇKKV) olarak adlandırılır (Hwang ve Yoon, 1981). ÇKKV problemleri de kişi, kurum veya kuruluşların gerçek hayatta sıkça karşılaştıkları durumlardır. Bu durumlara örnek verecek olursak kişi bazında; ev, meslek, otomobil, akıllı telefon, tablet, bilgisayar, mobilya seçimi vb. birçok örnek verilebilir. Kurum veya kuruluş bazında; tedarikçi, hammadde, vakıf, banka, üniversite vb. konusunda en iyilerinin seçilmesi ya da performanslarının değerlendirilmesi problemleri örnek olarak gösterilebilir.

ÇKKV problemlerinin birçok çeşidinin olmasına rağmen amaç (objective), nitelik (attributes), kriterler arası çatışma/çelişki, kıyaslanamaz birimler, tasarım veya seçimler, alternatifler, kriter ağılıkları ve karar matrisi çoğunda ortak olan özelliklerdir (Hwang ve Yoon, 1981; Triantaphyllou, 2000). ÇKKV yöntemlerinde kriter ağırlıklarının belirlenmesi karar verici tercihlerinin ortaya çıkarılmasındaki en önemli adımlardan biridir. Bu önemine binaen de geliştirilmiş birçok kriter 
ağırlıklandırma yöntemi bulunmaktadır (Malczewski, 1999; Zardari vd., 2014). Ayrıca kriter ağırlıklandırma yöntemleri ile ilgili birçok sınıflandırma yapılmıştır. Bu sınıflandırmaların en güncel ve kapsamlısını Wang vd. (2009) ile Ahn (2011)'ın geliştirmiş oldukları bilinmektedir. Öznel, nesnel ve karma olmak üzere üç grup oluşturulmuş bu sınıflandırmada; kriter ağırlıklarının karar verici tarafından belirlendiği yöntemler öznel, matematiksel model veya formüllerin yardımıyla belirlendiği yöntemler nesnel, öznel ve nesnel yöntemleri birbirine entegre ederek kullanan yöntemlere de karma kriter ağırlıklandırma yöntemleri olarak isimlendirilmiştir. Bu çalışmada kullanılacak olan Max100, SWARA ve İkili Karşılaştırma yöntemleri yapı gereği kriter önemleri karar vericiler tarafından belirlendiğinden, öznel kriter ağılıklandırma yöntemleri olarak da bilinmektedir. Bu bağlamda yapılan literatür taraması dikkate alındığında Eckenrode (1965), Schoemaker ve Waid (1982), Fischer (1995), Barron ve Barrett (1996a), Barron ve Barrett (1996b), Leon (1997), Hajkowicz vd. (2000), Pöyhönen ve Hämäläinen (2001), Öztürk ve Batuk (2007), Keršuliene vd. (2010), Ahn (2011), Riabacke vd. (2012), Iwaro vd. (2014), Zardari vd. (2014) ve Tayyar ve Durmuş (2017) kriter ağırlıklandırma yöntemleriyle yapılan çalışmaların büyük bir kısmını oluşturmaktadır. Yukarıda bahsi geçen çalışmalarda kriter ağırlıklandırma yöntemlerinin güvenilirlikleri, karar vericiyi tatmin düzeyleri, değişkenlik seviyeleri, dağılım aralıkları karşılaştırılmış ve gerçek hayata uygulanabilirlikleri incelenmiştir. Bu çalışmada ise Max100, SWARA ve İkili Karşılaştırma kriter ağılıklandırma yöntemlerinden elde edilen ağırlıkların tatmin ve karar verici görüşlerine yakınlık düzeyleri incelenecektir. Ayrıca bu ağırlıklar AHP ve TOPSIS yöntemlerinde kullanılıp elde edilen alternatif sonuçlarına olan etkileri araştırılacaktır. Bu bağlamda da çalışma Mahmoodzadeh vd. (2007), Lin vd. (2008), Dağdeviren vd. (2009), Tadić vd. (2010), Bhutia ve Phipon (2012) ve Vinodh vd. (2014) gibi AHP ve TOPSIS ile yapılan çalışmalardan ayrılmaktadır. İlgili çalışmalara bakıldığında AHP ve TOPSIS yöntemlerinin olağan ya da bulanık (fuzzy) halleriyle en iyi alternatifi seçmeye yönelik çalışmalar olduğu görülmektedir.

Bu çalışma son zamanlarda internet kullanımın da yaygınlaşması ile birlikte insanların geleneksel alışverişlerini internet üzerinden yapmaya başlamalarından dolayı online alışveriş siteleri ve bu sitelerin seçim kriterleri üzerinde uygulanacaktır. Bunun üzerine online alışveriş ile ilgili hazırlanmış olan Li ve Zhang (2002), Dündar vd. (2007), Turan (2008), Saydan (2008), Marangoz vd. (2012), Kaya ve Özen (2012), Özgüven (2012), Cavlak (2012), Aksoy ve Sever (2012), Cevher (2014) ve Yılmaz ve Tümtürk (2015) çalışmaları incelenmiştir. Bu çalışmalarda online alışveriş yapan tüketicilerin davranışları, online alışverişte güven problemi, tüketicilerin online alışveriş sitelerinde satın alma niyetleri, risk ve fayda algıları, online alışveriş sitelerinin bazı ÇKKV tekniklerine göre değerlendirilmesi şeklindeki konular araştırılıp incelenmiştir. Bu çalışmada ilgili kaynaklar incelendikten sonra Cavlak (2012)'ın yapmış olduğu çalışmadan faydalanılarak kriterler belirlenmiştir. Çalışmada ilgili kriterlerin değerleri Max100, SWARA ve ikili Karşılaştırma kriter ağılıklandırma yöntemleriyle belirlenip AHP ve TOPSIS yöntemlerinde kullanılarak en iyi alternatif ortaya çıkarılacaktır. Bunun yanında online alışveriş sitesi seçimindeki en önemli kriterler açığa çıkarılacak ve elde edilecek farklı sonuçlar karar vericilerin anket başında vermiş oldukları puanlar ile kıyaslanarak Max100, SWARA ve ikili Karşılaştırma yöntemlerinden hangisinin AHP ve TOPSIS yöntemleriyle Karar Verici görüşlerine daha yakın sonuçlar verdiğine ulaşır.

\section{Kullanılan Kriter Ağırıklandırma Yöntemleri}

Çalışmada kriter ağırlıklarını belirleme aşamasında Max100, SWARA ve ikili Karşılaştırma yöntemleri kullanılmıştır. İili Karşılaştırma yöntemi AHP içinde hali hazırda kullanılan bir yöntemdir. Bu çalışma sayesinde Max100 ve SWARA gibi iki farklı kriter ağırlıklandırma yönteminin 
AHP'de kullanılmasıyla sonuçlara ne kadar etkisi olduğu ve karar verici görüşlerine yakınlık seviyeleri bulunacaktır. Karar verici görüşleri ise anketin başında kriterlerin ve alternatiflerin ayrı ayrı ve toplamları yüz olacak şekilde doğrudan puanlanması ile elde edilmiştir. Her bir karar vericiden elde edilen bu puanların ortalaması alınarak ortaya çıkan nihai kriter ve alternatif puanlarının karar verici görüşlerini yansıtan en doğru sonuçlar olduğu varsayılmıştır.

\subsection{Max100}

Max100 yöntemi; Bottomley ve Doyle'un 2001 yılında yaptıkları çalışmada kullandıkları bir çeşit doğrudan puanlama yöntemidir. Bu yöntemde ilk olarak karar vericiden ilgili çalışmada kullanılan kriterlerden kendisine göre en önemli olana 100 puan vermesi istenir. Daha sonra ise diğer kriterlerin her birini ayrı ayrı 100 puan verdiği kriter ile kıyaslayarak 0-99 arasında puanlaması istenir ve tayin edilen puanlar ilgili kriterin karşısına yazılır (Tayyar ve Durmuş, 2017). Yöntemin daha iyi anlaşılabilmesi için çalışmadaki kullanışından örnek verilebilir;

Tablo 1: Max100 Yöntemi için Kriter Puanlama Tablosu

\begin{tabular}{|l|l|}
\hline Kriterler & Verilen Puan (0-100) \\
\hline Güvenilirlik/Gizlilik & \\
\hline lade Kolaylığı & \\
\hline Ödeme Kolaylığı & \\
\hline Müşteri Hizmetleri Performansı & \\
\hline
\end{tabular}

Tablo 1'de bu çalışmada online alışveriş ile ilgili kriterlerin Max100 yöntemindeki kullanım şeklini gösterilmektedir. Örneğin; karar verici lade kolaylığı kriterinin en önemli kriter olduğunu düşünüyorsa ona 100 puan vermeli ve daha sonra Güvenilirlik/Gizlilik kriterini İade Kolaylığı kriteri ile kıyaslayıp "Güvenilirlik/gizlilik kriteri İade Kolaylığı kriterine göre 75 puan eder" diyorsa karşısına 75 yazılacaktır. "Ödeme kolaylığı kriteri lade Kolaylığı kriterine göre 60 puan eder" diyorsa karşısına 60 yazılacaktır. Max 100 yöntemi; karar vericinin bu şekilde tüm kriterleri en önemli olarak belirlediği kriter ile tek tek kıyaslayıp puanlamasını ona göre yaptığı bir kriter ağırlıklandırma yöntemidir. Puanlama 0-100 puan arasında sınılıdır. Tüm kriter puanların toplanıp her bir kriterin toplam kriter puanına bölünmesiyle ağırlıklar elde edilir.

\subsection{SWARA}

SWARA (Step-wise Weight Assessment Ratio Analysis) yöntemi 2010 yılında ilk kez Kersuliene vd. tarafından "Selection of rational dispute resolution method by applying new step-wise weight assessment ratio analysis (SWARA)" isimli çalışmada kullanılmıştır. SWARA'da kriter ağırlıklarının belirlenmesi için kriterler arasındaki önem farlılıklarının belirlenmesini gerekmektedir (Kersuliene vd., 2010). SWARA'nın uygulanışı birkaç adımda şöyle açıklanabilir (Kersuliene vd., 2010; Zolfani ve Bahrami, 2014);

1. Adım: Kriterler ilgili uzmanlar tarafından önemlerine göre sıralanır (Her uzman kendine göre ayrı bir sıra oluşturur).

2. Adım: Belirlenen sıraların ortalamaları alınarak genel sıra oluşturulur.

3. Adım: Her bir uzman tarafından j. kriterin (j+1). kriterden ne kadar daha önemli olduğu saptanır ve bu önem farkının değeri yüzde 5 'in katları olacak şekilde atanır.

4. Adım: Ataması yapılan önem farklarının ortalamaları alınarak artarda gelen kriterler arasındaki genel önem farkları $(s j)$ belirlenir. 
5. Adım: Illk kritere 1 (bir) değeri atanırken diğer kriterlerin değerleri genel önem farklarına 1 eklenmiş haliyle yazılır.

6. Adım: illk kriterin değeri 1 olarak kalırken; diğer kriterlerin değerleri, kendinden önce gelen kriter değerinin, beşinci adımdaki kendi sırasına denk gelen kriter değerine bölünerek hesaplanır.

7. Adım: Bir önceki adımda elde edilen kriter değerleri toplamlarına bölünerek normalleştirilmiş nihai kriter ağırlıkları elde edilir.

4. Adım ve sonrası örnek yardımıyla şöyle gösterilebilir; KR1, KR2, KR3 ve KR4 olmak üzere dört kriter değerinin SWARA yöntemi uygulanarak hesaplanılmak istendiği varsayılsın. İlgili kriterlere ilk üç adımın uygulanmış olduğu düşünülerek dördüncü adım ve sonrası aşağıda verilen Tablo 2' de gösterilmiştir.

\section{Tablo 2: SWARA Yönteminin Örnek Bir Uygulama Tablosu}

\begin{tabular}{|c|c|c|c|c|}
\cline { 2 - 5 } \multicolumn{1}{c|}{} & 4. Adım & 5. Adım & 6. Adım & 7. Adım \\
\hline $\begin{array}{c}\text { Kriterler } \\
\text { (Önem Sı- } \\
\text { rası) }\end{array}$ & $\begin{array}{c}\text { Genel önem farkları } \\
\left(s_{j}\right)\end{array}$ & $\begin{array}{c}\text { Katsayı }\left(k_{j}=s_{j}+\right. \\
1)\end{array}$ & $\begin{array}{c}\text { Yeniden hesaplanan } \\
\text { ağırlıklar }\left(w_{j}=\right. \\
\left.x_{j-1} / k_{j}\right)\end{array}$ & $\begin{array}{c}\text { Normalleştirilmiş ni- } \\
\text { hai ağırlıklar }\left(q_{j}=\right. \\
\left.w_{j} / \sum w_{j}\right)\end{array}$ \\
\hline KR3 & 0,182 & 1 & 1 & 0,311 \\
\hline KR1 & 0,156 & 1,182 & 0,846 & 0,262 \\
\hline KR2 & 0,134 & 1,156 & 0,732 & 0,227 \\
\hline KR4 & 0,472 & 1,134 & 0,645 & 0,200 \\
\hline TOPLAM & 4,472 & 3,223 & $\mathbf{1}$ \\
\hline
\end{tabular}

SWARA yöntemi uzmanlardan veri toplamada ve koordine etmede faydalı bir yöntem olarak görülmektedir. Ayrıca, uzmanların kolayca birlikte çalışabileceği ve karmaşık olmayan bir yöntem olduğu düşünülmektedir (Zolfani vd., 2013; Zolfani ve Bahrami, 2014). Yukarıda anlatılanlardan da anlaşıldığı üzere SWARA yönteminde bir grup uzmanın verdikleri karar değerlerinin ortalamalarından yola çıkarak sonuca varıldığı görülmektedir. Bu çalışmada ise uzmanların belirlemiş oldukları sıralamaların ve önem farklarının ortalamaları alınmadan (2. Ve 4. Adım uygulanmadan) geriye kalan tüm adımları gerçekleştirerek her bir uzmanın vermiş oldukları bilgilere dayanarak ayrı ayrı kriter değerlerine ulaşılmıştır. Böylece SWARA yöntemi grup yerine bireysel ölçüde kullanılıp incelenmiştir (Tayyar ve Durmuş, 2017).

Çalışmada SWARA yöntemi kullanımı için kriterler isim sırasına göre verilip Tablo 3 içine önemlerine göre sırayla yazılması ve karşılarına kendisinden sonra gelen (ilk kriter hariç) kriter ile arasındaki önem farkının \%5'in katları olacak şekilde yazııması istenmiştir.

Tablo 3: SWARA Yöntemi için Kriter Puanlama Tablosu

\begin{tabular}{|c|c|l|}
\hline Sıra & \multicolumn{1}{|c|}{ Kriterler } & \multicolumn{1}{|c|}{ Önem Farkı (\%) } \\
\hline 1 & & $\mathbf{1 - 2}$ arasındaki: \\
\hline 2 & & $2-3$ arasındaki: \\
\hline 3 & $3-4$ arasındaki: \\
\hline 4 & & \\
\hline
\end{tabular}

Kriterler: Güvenilirlik/Gizlilik, İade Kolaylığı, Ödeme Kolaylığı, Müşteri Hizmetleri Performansı 
Örneğin; karar verici için önem sıralaması şöyle olsun; 1. Güvenilirlik/Gizlilik, 2. Ödeme Kolaylığı, 3. İade Kolaylığı ve 4. Müşteri Hizmetleri Performans. Karar verici önem sırasını belirledikten sonra 2. sıradaki kriterin karşısına 1. İle 2. kriter arasındaki önem farkını \%15 olarak belirlediyse 0,15 yazacaktır. 3. kriterin karşısına 2. ile 3. kriter arasındaki önem farkını \%25 olarak belirlediyse 0,25 yazacaktır. 4.kriterin karşısına da benzer işlem uygulanarak bir önem farkı yazılacaktır. Daha sonra bu değerler alınıp 5. Adımdan devam edilerek SWARA yönteminin nihai kriter ağırlıklarına ulaşıır.

\section{3. İkili Karşılaştırma}

Ikili Karşılaştırma yöntemi Saaty’nin 1977 yılındaki çalışmasında sunmuş olduğu hiyerarşi ve tutarsızlık indeksi sayesinde gerçek yaşam problemlerinde uygulanabilir hale getirilmiştir. İkili Karşılaştırma yöntemiyle ilgili yapılan uygulamalar doğrultusunda; herhangi bir kararın karşılaştırılmasında belirli bir standardın olmadığı ve doğrudan ölçümün mümkün veya uygun olmadığı durumlarda yöntemin önemli bir yere sahip olduğu görülmektedir (Kakiashvili vd., 2012).

İkili Karşılaştırma yöntemi için " $n$ " tane alternatifin göreceli ağırlıklarının (bir oran ölçeğine bağlı olduğu varsayılan) ikili olarak karşılaştırılmak istendiği varsayılsın. İkili karşılaştırmalar, aşağıdaki gibi bir matris ile temsil edilebilir:

$$
A=\left(a_{i j}\right)=\left[\begin{array}{cccc}
a_{11} & a_{12} & \cdots & a_{1 n} \\
a_{21} & a_{22} & \cdots & a_{2 n} \\
\vdots & \vdots & \ddots & \vdots \\
a_{n 1} & a_{n 2} & \cdots & a_{n n}
\end{array}\right]
$$

Bu matriste, i. kriter j. kriter ile karşılaştırıldığında $a_{i j}$ değerinin atandığı varsayılsın bu durumda j. kriterin i. kriter ile kıyaslanmasına gerek kalmadan $1 / a_{j i}$ değerini almaktadır. Bu da matris elemanlarının $a_{i j}=1 / a_{j i}$ şeklinde tersinin alınması (reciprocal) özelliğini karşıladığını göstermektedir (Koczkodaj, 1993; Saaty, 1977; Kurttilla vd., 2010). A matrisi ağırlıkların transpozu olan $w^{T} \equiv\left(w_{1}, \ldots, w_{n}\right)$ vektörü ile çarpıldığında $n w$ vektörüne eşit olduğu görülür. Böylece problem;

$$
A w=n w
$$

halini alır. (2) ifadesi de

$$
(A-n l) w=0
$$

şeklinde yazılabilir. Burada w ağırlıklarının bulunabilmesi için (3) denkleminin çözülmesi gerekir. Sistemin sıfırdan farklı bir çözümü varsa ancak ve ancak o zaman " $\mathrm{n}$ ”, A matrisinin özdeğeridir. Yani " $n$ ", A karakteristik denkleminin bir köküdür. Ayrıca her satır, ilk satırın sabit bir çarpımı olduğundan A matrisi birim sıraya sahiptir. Yani A matrisi satırları birbirinin bir skaler katı olan bir matristir. Aynı zamanda;

$$
\sum_{i=1}^{n} \lambda_{i}=\operatorname{tr}(A) \equiv \text { diagonal elemanların toplamı }=n
$$

olduğu bilinir. Bu sebeple $\lambda_{\max }=n$ ve $\lambda_{i}=0, \lambda_{i} \neq \lambda_{\max } \operatorname{dır}\left(\lambda_{i}, i=1, \ldots, n\right.$ olmak üzere A'nın biri hariç sıfır olan özdeğerleridir). $\lambda_{\text {max }} A$ matrisinin en büyük özdeğeridir (Saaty, 1977). Buradan yola çıkarak (3) denklemi; 


$$
\left(A-\lambda_{\max } I\right) w=0
$$

şeklinde ifade edilebilir. (5) denkleminin $\lambda_{\max }$ esas alınarak çözülmesiyle w özvektörü elde edilir (Tzeng ve Huang, 2011). Elde edilen w özvektörü kriterlerin önem sıralamalarının belirlenmesini sağlar (Cheng ve Li, 2004). Bunun dışında Saaty 1977 yılında yapmış olduğu çalışmada ikili karşılaştırmalarda kullanılmak üzere 25 farklı ölçek geliştirmiştir. Çalışmada gerçekleştirdiği uygulamalar sonucunda $9^{\prime} l u$ Likert ölçeğinin en iyi tutarlık sonucunu verdiği görülmüştür. Bu sebepten dolayı çalışma için 9'lu Likert ölçeği kullanılmıştır. Ayrıca, karar vericilerden elde edilen ikili karşılaştırma ağırlıklarının doğruluğunu tespit edebilmek amacıyla Tutarlılık Indeksi (Consistency Index(CI)) ve Tutarlılık Oranı (Consistency Ratio(CR)) olmak üzere iki indeks önerilmektedir. Tutarlılık indeksi aşağıdaki formül yardımıyla hesaplanabilir:

$$
C I=\left(\lambda_{\max }-n\right) /(n-1)
$$

Burada $\lambda_{\text {max }}$ daha önceden de belirtildiği gibi en büyük özdeğerdir, $\mathrm{n}$ ise toplam kriter sayısıdır. İkili karşılaştırmadan elde edilen göreceli ağırlıklardan güvenilir bir sonuç elde edilebilmesi için $\mathrm{Cl}$ değerinin 0,1'i aşmaması gerektiği belirtilmiştir (Saaty, 1980). Tutarlılık oranı ise aşağıdaki formül yardımıyla hesaplanabilir:

$$
C R=C I / R I
$$

Burada RI (Random Consistency Index), "Rassal Tutarlılık Indeksi” ni temsil etmektedir. Farklı boyuttaki matrislere (n) göre RI değerleri Tablo 4'de gösterilmiştir (Tzeng ve Huang, 2011).

Tablo 4: Rastgele Tutarlılık Indeksi

\begin{tabular}{|c|c|c|c|c|c|c|c|c|c|c|c|c|}
\hline $\mathrm{n}$ & 3 & 4 & 5 & 6 & 7 & 8 & 9 & 10 & 11 & & 12 & 13 \\
\hline $\begin{array}{l}\text { Rastgele } \\
\begin{array}{l}\text { Tutarlılık } \\
\text { Indeksi }\end{array}\end{array}$ & 0,52 & 0,89 & 1,11 & 1,25 & 1,35 & 1,40 & 1,45 & 1,49 & 1,51 & & 1,54 & 1,56 \\
\hline
\end{tabular}

Kaynak: Tzeng ve Huang, 2011.

Tzeng ve Huang (2011) güvenilir sonuçlara ulaşılması için tutarlılık oranının 0,1'in altında olması gerekirken, tolere edilebilir maksimum seviyenin 0,2 olduğu sonucuna varmışlardır.

Çalışmada İili Karşılaştırma yönteminin uygulaması için Tablo 5 kullanılmıştır:

Tablo 5: Ikili Karşılaştırma için Kriter Puanlama Tablosu

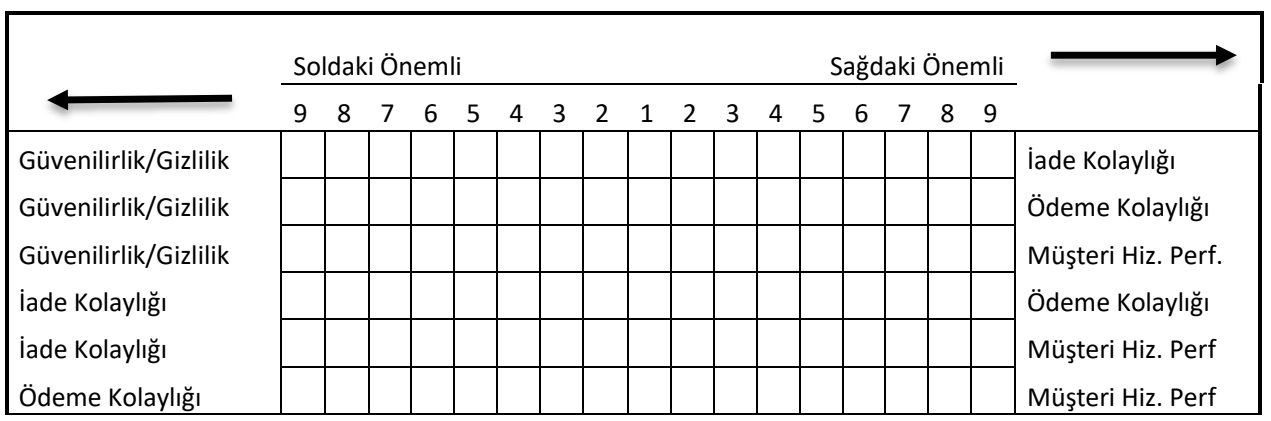

"1- Eşit Önemli, 3- Çok Az Önemli, 5- Kuvvetli Derecede Önemli, 7- Çok Kuvvetli Derecede Önemli, 9- Aşırı Derecede Önemli, 2, 4, 6, 8- Ara değerler" şeklindedir. 
Örneğin karar verici ilk satırda lade Kolaylığı kriterinin Güvenilirlik/Gizlilik kriterinden çok kuvvetli derecede önemli olduğunu düşünüyorsa sağ taraftaki 7'yi işaretlemesi gerekecektir. Benzer şekilde 4. satırda lade Kolaylığı kriterinin Ödeme Kolaylığı kriterinden kuvvetli dereceden bir tık daha üstte önemli olduğunu düşünüyorsa sol taraftaki $6^{\prime} y ı$ işaretleyecektir. Burada karar verici ve anketi uygulayan kişi tarafından dikkat edilmesi gereken en önemli şey önem değerlerinin atanırken tutarlıığında göz önünde bulundurulmasıdır. Yapılan puanlandırma sonucunda tutarlı bir sonuç elde edilmiyorsa karar vericiye dönülüp tekrar baştan puan ataması yapılmasının istenmesi gerekmektedir.

\section{Araştırmanın Yöntemi}

Çalışma için ilk olarak Güvenilirlik/Gizlilik, Ödeme Kolaylığı, Ürün Bilgisi ve Çeşitliliği, Web Sitesi Performansı olmak üzere alışveriş site seçiminde kullanılan (Cavlak, 2012) dört kriter ile Türkiye'de en çok tercih edilen ve bilinen hepsiburada.com, gittigidiyor.com ve n11.com alternatifleri belirlenmiştir. Bundan sonra ise AHP ve TOPSIS yöntemleri ile Max100, SWARA ve Ikili Karşılaştırma kriter ağırlıklandırma yöntemlerinin yapısı göz önünde bulundurularak ilgili kriter ve alternatiflerin yer aldığı anket düzenlenmiştir. Kriter ağırlıklandırma yöntemlerinin anket içinde nasıl uygulandığı bir önceki bölümde gösterilmiştir. Anket, anlama ve kavrama kapasitelerinin yüksek olmasının yanında sonuçların güvenilirliğinin de yüksek çıkmasını sağlaması bakımından ortalama olarak ayda en az bir kez online alışveriş yapan, gittigidiyor.com, hepsiburada.com ve n11.com sitelerinin üçünü de kullanan Uşak Üniversitesi akademisyenlerinden 31 kişi ile yüz yüze görüşülüp gerekli bilgilendirmeler yapılarak uygulanmıştır. Elde edilen anket sonuçları gerekli hesaplamalar yapılacak şekilde düzenlenip Excel'e girilerek veri seti oluşturulmuştur. Anket sonuçları ilk girildiği haliyle SPSS 18.0 programında kullanılmaya uygun olmadığı için öncelikle Excel üzerinde çeşitli formül ve işlemler uygulanmıştır. Excel'de yapılan işlemler aşağıda verilmiştir;

1. Adım: Kriter ağılıklarının hesaplanabilmesi için anketlerden elde edilen veriler 3. Bölümde açıklandığı şekilde Excel'e aktarılarak ilgili hesaplamalar yapılmış ve her bir yöntem için kriter ağırlıkları bulunmuştur.

2. Adım: Karar verici her bir kriter için alternatifleri ikili karşılaştırmıştır (Bu işlemde Tablo 5'e benzer şekilde bir ölçek kullanılmış ancak satırlarda alternatifler her bir kriter için karşılaştırılmıştır). Bu karşılaştırmadaki değerler kullanılarak karar matrisi elde edilmiştir.

3. Adım: Max100, SWARA ve İkili Karşılaştırma (IK) yöntemlerine göre AHP ve TOPSIS sonuçlarını elde etmek amacıyla her bir karar vericinin kriter ağırlıkları ve karar matrisi Excel'de ayrı bir çalışma sayfasına aktarılmıştır.

4. Adım: Max100-AHP,Max100-TOPSIS, SWARA-AHP, SWARA-TOPSIS, IK-AHP, IK-TOPSIS sonuçları her bir karar verici için hesaplanmıştır.

5. Adım: Karar vericilerin anket başında toplamları 100 olacak şekilde atamış oldukları kriter ve alternatif puanları ilgili kişilerin Excel çalışma sayfalarına eklenmiştir.

6. Adım: Her bir karar vericiye ait sonuçlar SPSS 18.0 programına aktarılmıştır.

Aynı katılımcının aynı anket üzerinde birden fazla yönteme göre değerlendirme yapmasından dolayı bu çalışmada, tekrarlı (bağımlı) örneklem söz konusudur. Karşılaştırılan değişkenlerin tümünün normal dağılıma uyması durumunda tek yönlü tekrarlı örnek varyans analizi, en az birinin normal dağılıma uymaması durumunda Friedman testi uygulanarak değişkenler arasında farklılık olup olmadığı sınanmıştır. Tek yönlü tekrarlı̈önek varyans analizi sonucunda değişkenler arasında anlamlı farklılıklar bulunduğunda, farkın hangi değişkenler arasında olduğunu bulmak için Bonferroni testi uygulanmıştır. Friedman testi sonucunda değişkenler arasında anlamlı 
farklılıklar bulunduğunda ise olası tüm ikili kombinasyonlarına Wilcoxon testi uygulanmıştır. Wilcoxon testi uygulanırken eş anlı pek çok test yapıldığından anlamlılık seviyesi \%1'e düşürülmüştür.

\section{Araştırmanın Bulguları}

Kriterlerin Karar Verici, Max100, ikili Karşılaştırma ve SWARA yöntemlerine göre ağırlık ortalamaları Şekil 1'de verilmiştir. Karar Verici görüşlerine göre Güvenilirlik/Gizlilik \%38,2'lik bir ortalamayla en yüksek ağılığı almaktadır. Bunu sırasıyla Ödeme Kolaylığı (\%23,3), Ürün Bilgisi ve Çeşitliliği $(\% 22,6)$ ve Web Sitesi Performansı $(\% 16,0)$ takip etmektedir. SWARA yönteminde kriter sıralaması Karar Verici görüşleri ile aynı çıkmasına rağmen az bir farkla ağırlık ortalamaları birbirinden farklı çıkmıştır. SWARA yönteminde \%32,6 Güvenilirlik/Gizlilik, \%24,1 Ödeme Kolaylığı, \%23,4 Ürün Bilgisi ve Çeşitliliği ve \%20,0 Web Sitesi Performansı ortalama ağılıkları elde edilmiştir. Max100 yönteminde çok ufak bir farkla Ürün Bilgisi ve Çeşitliliği kriteri Ödeme KolayIığının önüne geçmiştir. Kriter ağırlık ortalamalarına bakıldığında ise \%31,7 Güvenilirlik/Gizlilik, \%24,7 Ürün Bilgisi ve Çeşitliliği, \%24,4 Ödeme Kolaylığı ve \%19,2 Web Sitesi Performansı olduğu görülmüştür. İkili Karşılaştırma yönteminde ise, sıra Karar Verici görüşleri ile aynı olmasına rağmen ilk ve son sırada olan kriterlerde Karar Verici görüşlerinden oldukça farklı ağırlıklar bulunmuştur. İkili Karşılaştırma yönteminde \%46,8 Güvenilirlik/Gizlilik, \%23,3 Ödeme Kolaylığı, \%19,0 Ürün Bilgisi ve Çeşitliliği ve \%10,9 Web Sitesi Performansı ağılık ortalamaları elde edilmiştir.

Karar Verici' den anketin başında gittigidiyor.com, hepsiburada.com ve n11.com alternatiflerini ilgili dört kriteri baz alarak kendi görüşlerine en yakın olacak şekilde puanlandırmaları istenmiştir. Bu işlem yapılarak Karar Verici görüşlerini en doğru yansıttığı varsayılan alternatif ağılıklarının elde edilmesi amaçlanmıştır. Ankette Max100, SWARA ve İkili Karşılaştırma olmak üzere 3 farklı kriter ağırlıklandırma yöntemi bulunmaktadır. Bu yöntemlerden elde edilen kriter ağırlıkları AHP ve TOPSIS yöntemlerinde işleme alındığında karşımıza 6 farklı alternatif sonucu çıkmaktadır. Şekil 2'de yöntemlere göre alternatiflerin aldığı önem değerleri ile Karar Verici görüşlerinin ortalamaları verilmiştir. Alternatiflerin önem sırası incelendiğinde, İkili Karşılaştırma ağırlıklarının TOPSIS yöntemine uygulanması dışında kalan altı durumda, en iyi alternatif hepsiburada.com olarak bulunmuş bunu sırasıyla n11.com ve gittigidiyor.com takip etmiştir. Ikili Karşılaştırma ağırlıklarının TOPSIS yöntemine uygulandığı durumda ise en önemli alternatif değişmemiş, gittigidiyor.com ikinci ve n11.com üçüncü sırayı almıştır, ancak iki alternatifin puanları birbirine çok yakındır. En iyi alternatif olan hepsiburada.com'un Karar Verici ortalamalarına göre puanı, yöntemlerle elde edilen puanlardan düşük çıkarken, ikinci ve üçüncü sıradaki alternatiflerin Karar Verici puan ortalamaları yöntemlerden elde edilen puanlardan yüksek çıkmıştır.

Şekil 1: Karar Verici ve Kriter Ağırlıklandırma Yöntemlerine Göre Ortalama Kriter Ağırlıkları

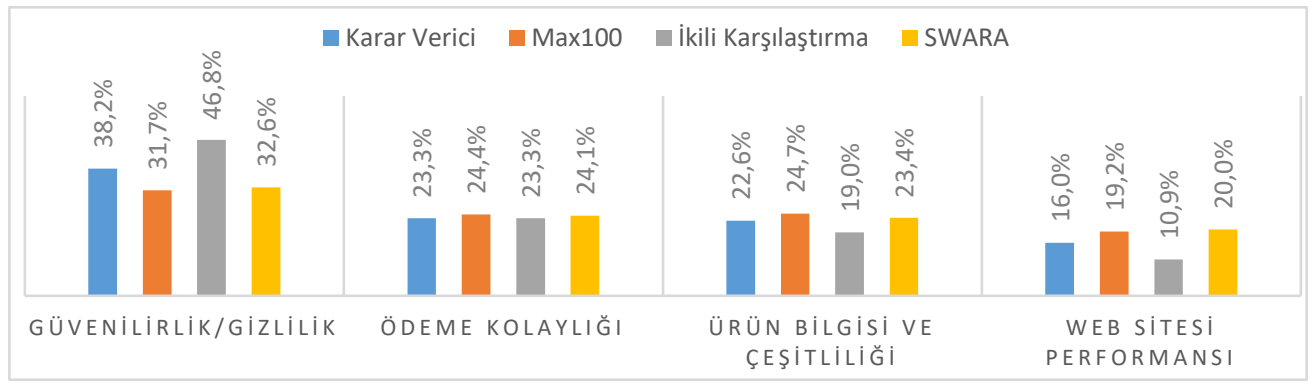




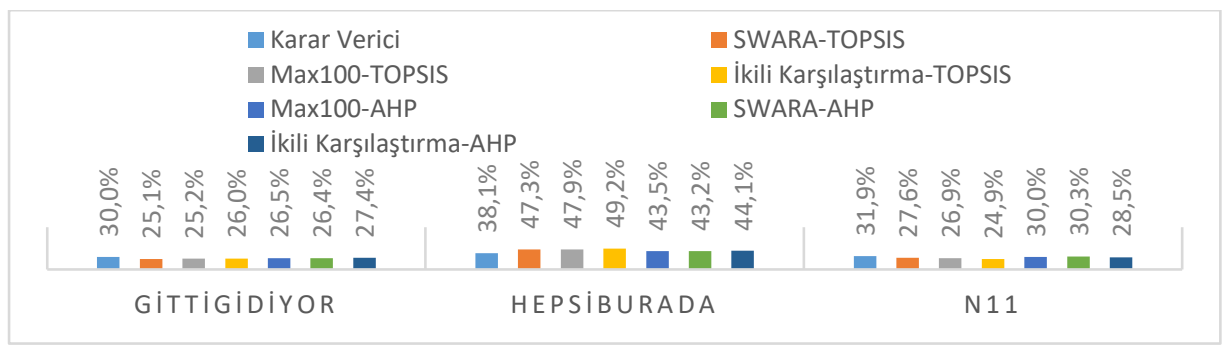

Şekil 2: Karar Verici ve Yöntemlere Göre Alternatiflerin Ortalama Ağırlıkları

\subsection{Karar Vericinin Vermiş Olduğu Kriter Ağırlıkları ile Yöntem Kriter Ağırıılarının Karşı- laştırılması}

Kriterlerin Karar Verici, Max100, íkili Karşılaştırma ve SWARA yöntemlerine göre kriter ağırlıklarının ortalamaları, standart sapmaları, Kolmogorov-Smirnov normal dağılıma uygunluk testi $p$ değerleri, karşılaştırma testi $p$ değerleri ve farklı gruplar Tablo 6 'da verilmiştir. Güvenilirlik/Gizlilik kriteri iç̧in değişkenlerin tümü normal dağılıma uygun olduğundan tek yönlü tekrarlı örnek varyans analizi uygulanmıştır. Testin p değerinin \%5'den küçük çıkması en az iki değişken arasında anlamlı farklıı̆ın olduğunu gösterir. Farkların hangi değişkenler arasında olduğunu tespit etmek için Bonferroni testleri uygulanmış ve Tablo 6'nın son sütunundan da görülebileceği gibi Max100 ve SWARA yöntemleri homojen olarak bulunmuş, bunun dışında kalan tüm ikililerin ise anlamlı farklı olduğu görülmüştür $(p<0,05)$. Bu nedenle En küçük ortalamaya sahip olan Max100 $(\% 31,65)$ ve SWARA $(\% 32,58)$ ağırlıklarının Karar Verici $(\% 38,16)$ ağırlığından küçük olduğuna, Karar Verici ağırlığının da İkili Karşılaştırma $(\% 46,78)$ ağırlığından küçük olduğuna karar verilebilir. Güvenilirlik/Gizlilik kriteri için Karar Verici görüşlerine en yakın yöntemin SWARA, ikinci Max100 en uzak kriter ağırlıklandırma yönteminin ise İkili Karşılaştırma olduğu görülmektedir.

Ödeme Kolaylığı kriteri için değişkenlerin tümü normal dağılıma uygun olduğundan tek yönlü tekrarlı örnek varyans analizi uygulanmıştır. Testin $p$ değerinin $\% 5$ 'den büyük çıkması ağırlıkların anlamlı bir farka sahip olmadığını gösterir. Ödeme Kolaylığı kriteri için ortalamalar incelendiğinde, Karar Verici $(\% 23,29)$, Max100 $(\% 24,37)$, ỉkili Karşılaştırma $(\% 23,26)$ ve SWARA $(\% 24,06)$, üç yönteminde kriter ağırlık ortalamalarının Karar Vericinin ortalama ağırlığına oldukça yakın değer aldığı görülmektedir.

Ürün Bilgisi ve Çeşitliliği kriteri için değişkenlerin tümü normal dağılıma uygun olduğundan tek yönlü tekrarlı örnek varyans analizi uygulanmıştır. Testin $p$ değerinin \%5'den küçük çıkması en az iki değişken arasında anlamlı farklılığın olduğunu gösterir. Farkların hangi değişkenler arasında olduğunu tespit etmek için Bonferroni testleri uygulanmış ve Tablo 6'nın son sütunundan da görülebileceği gibi en küçük ve en büyük ortalamaya sahip olan İkili Karşılaştırma ve Max100 yöntemleri farklı olarak bulunmuştur $(p<0,05)$. Bunun dışında kalan tüm ikili karşılaştırmaların farklı olmadığı görülmüştür. Ürün bilgisi ve çeşitliliği kriterinin ağırlık ortalamaları ele alındığında \%22,58 Karar Vericinin, \%24,73 Max100, \%23,39 SWARA ve \%19,05 ikili Karşılaştırma yöntemlerinin ağırlıklarıdır. Karar Verici kriter ağırlık ortalamasına en yakın yöntemin SWARA olduğu bunu sırasıyla Max100 ve İkili Karşılaştırmanın takip ettiği görülmüştür.

Web Sitesi Performansı kriteri için İkili Karşılaştırma ağırlıkları normal dağılıma uymadığından Friedman testi ile farklılıklar tespit edilmiştir. Testin $p$ değerinin \%5'den küçük çıkması en az iki ağılık arasında anlamlı farklılığın olduğunu gösterir. Farkların hangi değişkenler arasında 
olduğunu tespit etmek için olası her ikiliye Wilcoxon testleri uygulanmış ve Tablo 6'nın son sütunundan da görülebileceği gibi Max100 ve SWARA yöntemleri homojen olarak bulunmuş, bunun dışında kalan tüm ikililerin ise anlamlı farklı olduğu görülmüştür $(p<0,01)$. Bu nedenle en büyük ortalamaya sahip olan SWARA $(\% 19,97)$ ve Max100 $(\% 19,25)$ ağılıklarının Karar Verici $(\% 15,97)$ ağırlığından büyük olduğuna, Karar Verici ağırlığının da İkili Karşılaştırma $(\% 10,91)$ ağırlığından büyük olduğuna karar verilebilir. Web Sitesi Performansı kriteri için Karar Verici görüşlerine en yakın yöntemlerin Max100 ve SWARA olduğu görülmektedir.

Tablo 6: Kriterler için Karşılaştırmalar

\begin{tabular}{|c|c|c|c|c|c|c|}
\hline & Güvenilirlik/Gizlilik & Ortalama & S. Sapma & $\begin{array}{l}\text { K-S p de- } \\
\text { ğeri }\end{array}$ & $\begin{array}{l}\text { Varyans } \\
\text { Analizi p de- } \\
\text { ğeri }\end{array}$ & Farklı Gruplar \\
\hline 1 & Karar Verici & 0,3816 & 0,1485 & 0,4029 & \multirow{4}{*}{0,000} & $1-2,1-3,1-4$ \\
\hline 2 & Max100 & 0,3165 & 0,0940 & 0,7676 & & $2-3$ \\
\hline 3 & İkili Karşılaştırma & 0,4678 & 0,1882 & 0,1038 & & $3-4$ \\
\hline \multirow[t]{2}{*}{4} & SWARA & 0,3258 & 0,0852 & 0,3582 & & \\
\hline & Ödeme Kolaylığı & Ortalama & S. Sapma & $\begin{array}{l}\text { K-S p de- } \\
\text { ğeri }\end{array}$ & $\begin{array}{l}\text { Varyans } \\
\text { Analizi p de- } \\
\text { ğeri }\end{array}$ & Farklı Gruplar \\
\hline 1 & Karar Verici & 0,2329 & 0,1039 & 0,3139 & \multirow{4}{*}{0,774} & \multirow{4}{*}{ homojen } \\
\hline 2 & Max100 & 0,2437 & 0,0697 & 0,3324 & & \\
\hline 3 & İkili Karşılaştırma & 0,2326 & 0,1540 & 0,1306 & & \\
\hline \multirow[t]{2}{*}{4} & SWARA & 0,2406 & 0,0793 & 0,3406 & & \\
\hline & Ürün Bilgisi ve Çeşitliliği & Ortalama & S. Sapma & $\begin{array}{l}\text { K-S p de- } \\
\text { ğeri }\end{array}$ & $\begin{array}{l}\text { Varyans } \\
\text { Analizi p de- } \\
\text { ğeri }\end{array}$ & Farklı Gruplar \\
\hline 1 & Karar Verici & 0,2258 & 0,0884 & 0,3806 & \multirow{4}{*}{0,004} & $2-3$ \\
\hline 2 & Max100 & 0,2473 & 0,0771 & 0,4654 & & \\
\hline 3 & İkili Karşılaştırma & 0,1905 & 0,1317 & 0,1813 & & \\
\hline \multirow[t]{2}{*}{4} & SWARA & 0,2339 & 0,0713 & 0,8602 & & \\
\hline & Web Sitesi Performansı & Ortalama & S. Sapma & $\begin{array}{l}\text { K-S p de- } \\
\text { ğeri }\end{array}$ & $\begin{array}{l}\text { Friedman } \\
\text { Testi p de- } \\
\text { ğeri }\end{array}$ & Farklı Gruplar \\
\hline 1 & Karar Verici & 0,1597 & 0,0790 & 0,0827 & \multirow{4}{*}{0,000} & $1-2,1-3,1-4$ \\
\hline 2 & Max100 & 0,1925 & 0,0690 & 0,6874 & & $2-3$ \\
\hline 3 & İkili Karşılaştırma & 0,1091 & 0,1011 & 0,0290 & & $3-4$ \\
\hline 4 & SWARA & 0,1997 & 0,0484 & 0,9892 & & \\
\hline
\end{tabular}

\subsection{Karar Vericinin Alternatiflere Vermiş Olduğu Ağırlıkları ile Yöntem Ağırıklarının Kar- şılaştırılması}

Alternatiflerin Karar Verici, TOPSIS ve AHP yöntemlerinde Max100, İili Karşılaştırma ve SWARA yöntemlerine göre elde edilen kriter ağılıkları kullanılarak bulunan önem değerlerinin ortalamaları, standart sapmaları, Kolmogorov-Smirnov normal dağılıma uygunluk testi $p$ değerleri, karşılaştırma testi $p$ değerleri ve farklı gruplar Tablo 7'de verilmiştir. 
Kolmogorov-Smirnov testi ile gittigidiyor.com alternatif değerlerine normal dağılıma uygunluk testi uygulandı ve İkili Karşılaştırma-TOPSIS ve İkili Karşılaştırma-AHP önem değerlerinin normal dağılıma uygunluk göstermediği görüldü. Bu nedenle Friedman testi uygulanarak önem değerleri arasındaki farklar incelendi. Yapılan test sonucunda $p$ değeri \%5'ten küçük çıkmıştır. Hangi önem değerlerinin farklı olduğunu görebilmek için olası tüm ikili kombinasyonlara toplam 21 adet Wilcoxon testi uygulanmıştır. Testin $p$ değerleri tüm durumlarda \%1'den büyük çıkmıştır. Bu nedenle gittigidiyor.com alternatifi önem değerlerinin farlılık göstermediği söylenebilir. Ortalamalar incelendiğinde TOPSIS yöntemiyle bulunan önem değerlerinin \%25,09 ile \%25,96 arasında olduğu, AHP yöntemiyle bulunan önem değerlerinin \%26,42 ile \%27,35 arasında olduğu ve Karar Vericilere göre önem değeri ortalamasının \%30,00 olduğu görülür.

hepsiburada.com alternatifi önem değerlerinin tümü normal dağılıma uygunluk gösterdiğinden önem değerleri arasında anlamlı bir farklılık olup olmadığını bulabilmek için tek yönlü tekrarlı örnek varyans analizi uygulanmıştır. Test sonucunda $p$ değeri $\% 5$ 'ten büyük çıktığı için hepsiburada.com alternatifi önem değerleri arasında anlamlı bir farklılık olmadığı söylenebilir. Ortalamalar incelendiğinde TOPSIS yöntemiyle bulunan önem değerlerinin \%47,26 ile \%49,18 arasında olduğu, AHP yöntemiyle bulunan önem değerlerinin \%43,16 ile \%44,10 arasında olduğu ve Karar Vericilere göre önem değeri ortalamasının \%38,06 olduğu görülür.

n11.com alternatifi önem değerlerinin tümü normal dağılıma uygunluk gösterdiğinden önem değerleri arasında anlamlı bir farklılık olup olmadı̆̆ını bulabilmek için tek yönlü tekrarlı örnek varyans analizi uygulanmıştır. Test sonucunda $p$ değeri \%5'ten büyük çıktığı için hepsiburada.com alternatifi önem değerleri arasında anlamlı bir farklııı olmadığı söylenebilir. Ortalamalar incelendiğinde TOPSIS yöntemiyle bulunan önem değerlerinin \%24,86 ile \%27,64 arasında olduğu, AHP yöntemiyle bulunan önem değerlerinin $\% 28,48$ ile $\% 30,32$ arasında olduğu ve Karar Vericilere göre önem değeri ortalamasının \%31,94 olduğu görülür.

Tablo 7: Alternatifler için Karşılaştırmalar

\begin{tabular}{|c|c|c|c|c|c|c|}
\hline & & & & & Friedman & \\
\hline & gittigidiyor.com & Ortalama & S. Sapma & $\begin{array}{l}\text { K-S p de- } \\
\text { ğeri }\end{array}$ & $\begin{array}{l}\text { Testi p de- } \\
\text { ğeri }\end{array}$ & Farklı Gruplar \\
\hline 1 & Karar Verici & 0,3000 & 0,1602 & 0,2833 & & \\
\hline 2 & SWARA-TOPSIS & 0,2509 & 0,2582 & 0,2364 & & \\
\hline 3 & Max100-TOPSIS & 0,2524 & 0,2570 & 0,1076 & & \\
\hline 4 & İkili Karşılaştırma-TOPSIS & 0,2596 & 0,2861 & 0,0392 & 0,006 & homojen \\
\hline 5 & Max100-AHP & 0,2653 & 0,1594 & 0,1003 & & \\
\hline 6 & SWARA-AHP & 0,2642 & 0,1598 & 0,1207 & & \\
\hline 7 & İkili Karşılaştırma-AHP & 0,2735 & 0,1771 & 0,0378 & & \\
\hline & hepsiburada.com & Ortalama & S. Sapma & $\begin{array}{l}\text { K-S p de- } \\
\text { ğeri }\end{array}$ & $\begin{array}{l}\text { Varyans Ana- } \\
\text { lizi p değeri }\end{array}$ & Farklı Gruplar \\
\hline 1 & Karar Verici & 0,3806 & 0,1769 & 0,7252 & & \\
\hline 2 & SWARA-TOPSIS & 0,4726 & 0,3019 & 0,6625 & & \\
\hline 3 & Max100-TOPSIS & 0,4786 & 0,3037 & 0,3874 & 0,330 & nomojen \\
\hline 4 & İkili Karşılaştırma-TOPSIS & 0,4918 & 0,3176 & 0,7001 & & \\
\hline
\end{tabular}




\begin{tabular}{|c|c|c|c|c|c|c|}
\hline 5 & Max100-AHP & 0,4352 & 0,2113 & 0,8997 & & \\
\hline 6 & SWARA-AHP & 0,4316 & 0,2106 & 0,8380 & & \\
\hline 7 & İkili Karşılaştırma-AHP & 0,4410 & 0,2180 & 0,8200 & & \\
\hline & n11.com & Ortalama & S. Sapma & $\begin{array}{l}\text { K-S p de- } \\
\text { ğeri }\end{array}$ & $\begin{array}{l}\text { Varyans Ana- } \\
\text { lizi p değeri }\end{array}$ & Farklı Gruplar \\
\hline 1 & Karar Verici & 0,3194 & 0,1558 & 0,6432 & \multirow{7}{*}{0,068} & \multirow{7}{*}{ homojen } \\
\hline 2 & SWARA-TOPSIS & 0,2764 & 0,2429 & 0,6660 & & \\
\hline 3 & Max100-TOPSIS & 0,2690 & 0,2455 & 0,6093 & & \\
\hline 4 & İkili Karşılaştırma-TOPSIS & 0,2486 & 0,2504 & 0,2598 & & \\
\hline 5 & Max100-AHP & 0,2995 & 0,1773 & 0,8121 & & \\
\hline 6 & SWARA-AHP & 0,3032 & 0,1753 & 0,9046 & & \\
\hline 7 & İkili Karşılaştırma-AHP & 0,2848 & 0,1787 & 0,9044 & & \\
\hline
\end{tabular}

\section{Tartışma ve Sonuç}

Karar Verici görüşlerine en yakın sonuçları veren kriter ağırlıklandırma yöntemlerini ve ÇKKV yöntemlerini öğrenebilmek amacıyla yapılan bu çalışmada Türkiye'nin en çok tercih edilen online alışveriş sitelerinin başında gelen gittigidiyor.com, hepsiburada.com ve n11.com sitelerinin Güvenilirlik/Gizlilik, Ödeme Kolaylığı, Ürün Bilgisi ve Çeşitliliği, Web Sitesi Performansı kriterleri göz önünde bulundurularak karşılaştırılması yapılmıştır.

Elde edilen bulgular dikkate alındığında Karar Verici ve üç kriter ağırlıklandırma yöntemine göre de en yüksek ağırlık ortalamasına Güvenilirlik/Gizlilik kriterinin sahip olduğu görülmektedir. Bu da insanların online alışveriş yaparken en çok alışveriş yaptıkları sitenin güvenilirliğine dikkat ettiklerini göstermektedir. Benzer şekilde Web sitesi performansı da tüm değerlendirmelerde sonuncu sırada yer almıştır. Bu da online alışverişte kişilerin sitenin kullanım kolaylığına, istedikleri ürünlere hızlı bir şekilde ulaşabilme özelliğine ya da sitenin tasarımına diğer kriterlere oranla çok fazla dikkate almadığını göstermektedir. Kapıda ödeme imkânı, taksitli alışveriş imkânı, peşin fiyatına taksit vb. özellikleri karşılayan ödeme kolaylığı kriterinin, başta Karar Verici görüşleri olmak üzere SWARA ve ikili Karşılaştırma yöntemlerinde de ikinci sırada yer alması bu kriterin ürün bilgisi ve çeşitliliği, web sitesi performansı kriterlerine göre online alışverişte daha çok önemsediğini göstermektedir.

Kriter ağırlık ortalamalarını göz önünde bulundurarak Karar Verici ve üç kriter ağırlıklandırma yönteminin sonuçları karşılaştırıldığında anlamlı farklııkların en çok önemli kriter olan Güvenilirlik/Gizlilik kriteri ile en az önemli kriter olan Web Sitesi Performansı kriterlerinde olduğu görülür. Güvenilirlik/Gizlilik Kriteri için Max100 ve SWARA en düşük ortalamalara sahipken bunu Karar Verici ve İili Karşılaştırmanın ortalamaları takip etmiştir. Web Sitesi Performansı kriteri için ise tam tersi bir sıralama oluşmuştur, ikili Karşılaştırmanın ortalaması en küçükken bunu sırasıyla Karar Vericinin ortalaması, Max100 ve SWARA yöntemleri takip etmiştir. Tüm kriterler için yapılan karşılaştırmalarda SWARA ve Max100 sonuçları daima homojen sonuçlar vermiştir. Max100 ve SWARA'nın birbirine yakın ve ikili karşılaştırmadan farklı sonuçlar vermesi Tayyar ve Durmuş'un (2017) çalışmasında da gözlemlenmiştir.

gittigidiyor.com, hepsiburada.com ve n11.com alternatiflerinin Karar Verici ve diğer altı farklı sonucu dikkate alındığında hepsiburada.com sitesinin katılımcı görüşleri ve belirlenen kriterlere göre en iyi online alışveriş sitesi olduğu görülmektedir. İkinci sırada n11.com ve üçüncü sırada ise gittigidiyor.com sitesinin olduğu sonucuna ulaşılmıştır. Karar Verici ve diğer altı farklı 
sonuç arasında istatistiksel olarak anlamlı fark olmamasına rağmen alternatif önem sıraları dikkate alınarak bir inceleme yapıldığında önemli bulgulara ulaşılabilir. Birinci sıradaki alternatif olan hepsiburada.com' un sonuçları incelendiğinde Karar Verici puanının diğer altı sonuçtan küçük olduğu, AHP yöntemiyle elde edilen üç sonucun birbirine oldukça yakın puanlarla Karar Vericinin puanını takip ettiği ve TOPSIS yöntemi ile elde edilen üç sonucun da yine birbirine oldukça yakın puanlarla en büyük değerlere sahip olduğu görülmektedir. İkinci ve üçüncü sıradaki alternatifler olan n11.com ve gittigidiyor.com için ise Karar Verici puanının en büyük puan olduğu AHP yöntemiyle elde edilen üç sonucun birbirine oldukça yakın puanlarla Karar Vericinin puanına yakın olduğu ve TOPSIS yöntemi ile elde edilen üç sonucun da yine birbirine oldukça yakın puanlarla en küçük değerlere sahip olduğu görülmektedir. Buradan hareketle örneklem hacminin arttırılması durumunda istatistiksel olarak anlamlı bulunmayan farkların birbirine en uzak ortalamalardan başlayarak anlamlı hale geleceği ve bu sayede kullanılan kriter ağırlıklandırma yöntemlerinden hangilerinin ÇKKV teknikleriyle en tatmin edici sonuçlar verdiği bilgisine ulaşılabileceği düşünülmektedir.

Tüm bu sonuçlara göre kriter ağırlıklandırma yöntemleri içerisinde Max100 ve SWARA yöntemlerinin íkili Karşılaştırma yöntemine göre Karar Vericinin görüşlerine daha yakın sonuçlar verdiği söylenilebilir. Bu sayede AHP veya TOPSIS yöntemlerinde bu zamana kadar kullanılan İkili Karşılaştırma yönteminin yerine daha az vakit alacağı ve karar verici görüşlerine daha yakın sonuçlar verebileceği düşüncesiyle Max100 ve SWARA yöntemlerinin kullanılabileceği sonucuna varılmıştır. ÇKKV yöntemlerinde ise AHP'nin TOPSIS'e göre Karar Vericinin görüşlerine daha yakın sonuçlar verdiği görülür. Sonuç olarak Karar Vericinin görüşlerine en yakın sonuçlar elde etmek isteniyorsa bir hibrit yaklaşım önerilebilir. Bu yaklaşıma göre kriter ağırlıklarının belirlenmesinde Max100 ya da SWARA kullanılarak kriter ağırlıkları belirlenmeli ardından bu ağırlıklar kullanılarak AHP yöntemi ile performans değerlendirilmesi yapılmalıdır. Bu sonuçların yalnızca üç alternatif ve dört kriter içeren nispeten küçük bir ÇKKV problemi için ve 31 katılımcının sonuçlarına dayanılarak elde edildiği göz önünde bulundurulmalıdır. Problemdeki alternatif ve kriter sayılarının az olması ve problemin anlaşılabilir ve kolay olmasından dolayı Karar Verici tercihlerinin doğru olduğu varsayımında bulunulabilir. Max100 ve SWARA kriter ağılıklandırma yöntemlerinin ilk kez bu çalışmada AHP ve TOPSIS içinde kullanılması, bununla birlikte sonuçların karar verici görüşlerine İkili Karşılaştırma yöntemine göre daha yakın çıkması ÇKKV alanına getirilen bir fayda olarak görülebilir.

Bu çalışmanın kısıtları küçük bir ÇKKV problemini konu alması ve nispeten küçük bir örneklemle çalışılmasıdır. Örneklem hacminin arttırılması durumunda istatistiksel olarak anlamlı bulunmayan farkların birbirine en uzak ortalamalardan başlayarak anlamlı hale geleceği umulabilir. Problemdeki alternatif ve kriter sayılarının arttırılması ve diğer ağırlık belirleme yöntemleri ile ÇKKV yöntemlerinin çalışmaya dâhil edilmesi durumunda nasıl bir sonuçla karşılaşılacağı araştırılması gereken bir konudur. 


\section{Kaynaklar}

Ahn, B. S. (2011). Compatible weighting method with rank order centroid: Maximum entropy ordered weighted averaging approach. European Journal of Operational Research, 212(3), 552-559.

Aksoy, R., ve Sever, H. (2012). Elektronik pazarlarlarda güven problemi ve kriminal faaliyetler. EJOVOC: Electronic Journal of Vocational Colleges, 2(1), 154-164.

Barron, F. H., ve Barrett, B. E. (1996a). Decision quality using ranked attribute weights. Management science, 42(11), 1515-1523.

Barron, F. H., ve Barrett, B. E. (1996b). The efficacy of SMARTER-Simple multi-attribute rating technique extended to ranking. Acta Psychologica, 93(1), 23-36.

Bhutia, P. W., ve Phipon, R. (2012). Appication of ahp and topsis method for supplier selection problem. IOSR Journal of Engineering (IOSRJEN) Volume, 2, 43-50.

Bottomley, P. A., \& Doyle, J. R. (2001). A comparison of three weight elicitation methods: Good, better, and best. Omega. 29, 553-560.

Cavlak, E. (2012). Onlıne alışveriş sitesi tercihinde etkili olan kriterlerin belirlenmesine ve önceliklendirilmesine yönelik bir karar modeli. Fen Bilimleri Enstitüsü, İstanbul Teknik Üniversitesi.

Cevher, E. (2014). Internette girişimciliğin yeni boyutu: Alışveriş kulüpleri siteleri ve bu siteler üzerine bir araştırma. Manas Journal of Social Studies, 3(3), 47-60.

Cheng, E. W. L. \& Li, H. (2004). Contractor selection using the analytic network process. Construction Management and Economics, 22, 1021- 1032.

Dağdeviren, M., Yavuz, S., ve Kılınç, N. (2009). Weapon selection using the AHP and TOPSIS methods under fuzzy environment. Expert Systems with Applications, 36(4), 8143-8151.

Dündar, S., Ecer, F., ve Özdemir, Ş. (2007). FuzzyTOPSis yöntemi ile sanal mağazaların web sitelerinin değerlendirilmesi. Atatürk Üniversitesi Iktisadi ve Idari Bilimler Dergisi, 21(1), 287-305.

Eckenrode, R. T. (1965). Weighting multiple criteria. Management science, 12(3), 180-192.

Fischer, G. W. (1995). Range sensitivity of attribute weights in multiattribute value models. Organizational Behavior and Human Decision Processes, 62(3), 252-266.

Forman, E. H., ve Selly, M. A. (2001). Decision by objectives: how to convince others that you are right: World Scientific.

Hajkowicz, S. A., McDonald, G. T., ve Smith, P. N. (2000). An evaluation of multiple objective decision support weighting techniques in natural resource management. Journal of Environmental Planning and Management, 43(4), 505-518.

Hwang, C. L., ve Yoon, K. (1981). Multiple attribute decision making: Methods and applications a state-of-the-art survey: Springer Berlin Heidelberg.

Iwaro, J., Mwasha, A., Williams, R. G., ve Zico, R. (2014). An Integrated Criteria Weighting Framework for the sustainable performance assessment and design of building envelope. Renewable and Sustainable Energy Reviews, 29, 417434.

Kakiashvili, T., Koczkodaj W. W. \& Woodbury Smith, M. (2012). Improving the medical scale predictability by the pairwise comparisons method: Evidence from a clinical data study. Computer Methods and Programs im Biomedicine, 105(3), 210-216.

Kaya, İ., ve Özen, H. (2012). Geleneksel mağazalar ile internetten alışverişte değer algısı ve satınalma niyeti: Bir karşılaştırma. Journal of the School of Business Administration, Istanbul University, 41(1), 13-30.

Keršuliene, V., Zavadskas, E. K., ve Turskis, Z. (2010). Selection of rational dispute resolution method by applying new step-wise weight assessment ratio analysis (SWARA). Journal of Business Economics and Management, 11(2), 243258.

Koczkodaj, W. W. (1993). A new definition of consistency of pairwise comparisons. Mathematical and computer modelling, 18(7), 79-84.

Kurttila, M., Pesonen, M., Kangas, J., \& Kajanus, M. (2000). Utilizing the analytic hierarchy process (AHP) in SWOT analysis-a hybrid method and its application to a forest-certification case. Forest policy and economics, 1(1), 41-52.

Leon, O. G. (1997). On the death of SMART and the birth of GRAPA. Organizational Behavior and Human Decision Processes, 71(3), 249-262.

Li, N., ve Zhang, P. (2002). Consumer online shopping attitudes and behavior: An assessment of research. AMCIS 2002 Proceedings, 508-517. 


\section{Eskişehir Osmangazi Üniversitesi Iïß Dergisi}

Lin, M. C., Wang, C. C., Chen, M. S., ve Chang, C. A. (2008). Using AHP and TOPSIS approaches in customer-driven product design process. Computers in industry, 59(1), 17-31.

Mahmoodzadeh, S., Shahrabi, J., Pariazar, M., ve Zaeri, M. (2007). Project selection by using fuzzy AHP and TOPSIS technique. World Academy of Science, Engineering and Technology, 30, 333-338.

Malczewski, J. (1999). GIS and multicriteria decision analysis: John Wiley \& Sons.

Marangoz, M., Yeşildağ, B., ve Saltık, I. A. (2012). E-ticaret işletmelerinin web ve sosyal ağ sitelerinin İçerik Analizi yöntemiyle incelenmesi. Journal of Internet Applications \& Management/Internet Uygulamaları ve Yönetimi Dergisi, 3(2), 53-78.

Özgüven, N. (2012). Promethee sıralama yöntemi ile özel alisveris siteleri üzerine bir arastirma. Selçuk Üniversitesi Sosyal Bilimler Enstitüsü Dergisi(27), 195-201.

Öztürk, D., ve Batuk, F. (2007). Criterion weighting in multicriteria decision making. Journal of Engineering and.

Pöyhönen, M., ve Hämäläinen, R. P. (2001). On the convergence of multiattribute weighting methods. European Journal of Operational Research, 129(3), 569-585.

Riabacke, M., Danielson, M., ve Ekenberg, L. (2012). State-of-the-art prescriptive criteria weight elicitation. Advances in Decision Sciences, 2012.

Saaty, T. L. (1977). A scaling method for priorities in hierarchical structures. Journal of Mathematical Psychology, 15, 234-281.

Saaty, T.L. (1980) The Analytic Hierarchy Process, New York: McGraw Hill. International, Translated to Russian, Portuguese, and Chinese, Revised editions, Paperback (1996, 2000), Pittsburgh: RWS Publications.

Saydan, R. (2008). Tüketicilerin online alışverişe yönelik risk ve fayda algılamaları: Geleneksel ve online tüketicilerin karşılaştırılması. Elektronik Sosyal Bilimler Dergisi, 23(23).

Schoemaker, P. J., ve Waid, C. C. (1982). An experimental comparison of different approaches to determining weights in additive utility models. Management science, 28(2), 182-196.

Tadić, D., Arsovski, S., Stefanovic, M., ve Aleksic, A. (2010). A fuzzy AHP and TOPSIS for ELV dismantling selection. International Journal for quality research, 4(2).

Tayyar, N. ve Durmuş, M. (2017). Comparison of max100, SWARA and pairwise weight elicitation methods. International Journal of Engineering Research and Applications (IJERA), 7(2), 67-78.

Triantaphyllou, E. (2000). Multi-criteria decision making methods Multi-criteria Decision Making Methods: A Comparative Study (pp. 5-21): Springer.

Turan, A. H. (2008). İnternet alışverişi tüketici davranışını belirleyen etmenler: geliştirilmiş Teknoloji Kabul Modeli (ETAM) ile bir model önerisi. Akademik Bilişim, 723-731.

Tzeng, G. H. \& Huang, J. J. (2011). Multi Attribute Decision Making: Methods and Applications. CRC Press, USA.

Vinodh, S., Prasanna, M., ve Prakash, N. H. (2014). Integrated fuzzy AHP-TOPSIS for selecting the best plastic recycling method: a case study. Applied Mathematical Modelling, 38(19), 4662-4672.

Wang, J. J., Jing, Y. Y., Zhang, C. F., ve Zhao, J. H. (2009). Review on multi-criteria decision analysis aid in sustainable energy decision-making. Renewable and Sustainable Energy Reviews, 13(9), 2263-2278.

Yılmaz, C., ve Tümtürk, A. (2015). İnternet üzerinden alışveriş niyetini etkileyen faktörlerin genişletilmiş teknoloji kabul modeli kullanarak incelenmesi ve bir model önerisi. Journal of Management \& Economics, 22(2).

Zardari, N. H., Ahmed, K., Shirazi, S. M., ve Yusop, Z. B. (2014). Weighting methods and their effects on multi-criteria decision making model outcomes in water resources management: Springer.

Zolfani, S. H., Aghdaie, H. M., Derakhti, A., Zavadskas, E. K. \& Varzandeh, M. H. M. (2013). Decision making on business issues with foresight perspective; an application of new hybrid MCDM model in shopping mall locating. Expert Systems with Applications, 40, 7111-7121.

Zolfani, S. H. \& Bahrami, M. (2014). Investment prioritizing in high tech industries based on SWARA-CORPAS approach. Technological and Economic Development of Economy, 20(3), 534-553. 